\title{
Treatment of children's proximal radioulnar joint fusion through single dual-plane osteotomy on combination with multi-sequence cast - a new method for treating the children's proximal radioulnar joint fusion
}

\author{
Haoqi CAI ${ }^{1}$, Zhigang $\mathrm{WANG}^{1 *}$ (D), Haiqing $\mathrm{CAI}^{1}$
}

\begin{abstract}
To introduce an improved method of de-rotation osteotomy for treating the congenital proximal radioulnar joint fusion: single dual-plane osteotomy combined with multi-sequence cast. Twelve child patients with congenital proximal radioulnar joint fusion (16 limbs) had been treated from 2014 to 2017 with single dual-plane osteotomy combined with multi-sequence cast method. 12 of 16 limbs were corrected in position after one-time cast change, and the remaining 4 limbs of two patients needed to receive cast change for two times before correction. Neither one suffered related nervous and vascular complications, nor one suffered ischemic contracture after all the cases received cast fixation, and it took 8 weeks for their osteotomy parts to reach bony union averagely after operation. The affected limb's functional evaluation before operation was averagely 5.75 scores (4 8); 12 movements could be completed fully after operation, i.e., functional evaluation reached 12 scores. This surgical operation is easy to operate with good operation result and big range of correction. It can also effectively avoid the occurrence of angioneurotic complications after operation with a high safety. Therefore, it is an ideal alternative method to treat the congenital proximal radioulnar joint fusion in the present stage when joint fusion dissociation operation is not matured.
\end{abstract}

Keywords: congenital; radioulnar synostosis; congenital proximal radioulnar synostosis; rotational osteotomy; osteotomy.

Practical Application: This surgical operation is easy to operate, with good operation result and big range of correction.

\section{Introduction}

There are many clinical reports about the treatment of congenital proximal radioulnar joint fusion, and rotary osteotomy has the optimum treatment effect at present, most of which combine internal fixation with a locking plate or intramedullary fixation with a kirschner wire through crossing. However, single dual-plane osteotomy on combination with multi-sequence cast operation method was adopted in this clinical study for treating children's proximal radioulnar joint fusion instead of internal fixation, and better effect had been obtained. This study has innovation and significant clinical guiding significance as it has not been reported yet at present. This paper introduces the operation method of treatment of children's proximal radioulnar joint fusion through single dual-plane osteotomy combined with multi-sequence cast, and evaluates its preliminary curative effect and method. Congenital proximal radioulnar joint fusion is a rare upper limb deformity: the range of joint motion is lost due to the congenital fusion of proximal radioulnar joint, causing the loss of child patient's forearm rotation function. The patient's daily life will be influenced seriously (Ramachandran et al., 2005) when the deformity is serious and forearm pronation angle is bigger. It's reported that, about $50-80 \%$ patients have suffered bilateral involvement or extreme pronation, and their forearm functions are greatly affected. For example, they cannot send the food to their months and also cannot flat their palms to accept the items (Simmons et al., 1983). However, dysfunction may appear rarely when the forearm is fixed in the less-pronation position and even in the neutral position as the rotation movements of shoulder and wrist on the same side may effectively compensate the forearm rotation (Cleary \& Omer, 1985).

\section{Data and methods}

\subsection{General data}

Twelve child patients with congenital proximal radioulnar joint fusion (16 limbs) had been treated in the period from 2014 to 2017 in our hospital with single dual-plane osteotomy combined with multi-sequence cast method.

\subsection{Evaluation method}

The recommended method was adopted while measuring forearm pronation angle: with elbow bending $90^{\circ}$, elbow joint clinging to two sides of chest, the included angles Ogino \& Hikino (1987) of radius and ulna belonoid lines and humeral shaft axis were measured with protractor (Figure 1 and 2).

Before the operation, 12 essential activities of daily living were evaluated functionally with Shingade et al., (2014) method. See Table 1. 
Table 1. Evaluation of each child for 12 essential activities of daily living.

\begin{tabular}{|c|c|c|}
\hline \multirow{2}{*}{ Sr. No. } & \multirow{2}{*}{ Activities of Daily Living } & \multirow{2}{*}{$\begin{array}{c}\text { Difficulty Present: } \\
\text { Score } 1 \\
\text { Difficulty Absent: } \\
\text { Score } 0\end{array}$} \\
\hline & & \\
\hline 1 & Taking food to the mouth & $1 / 0$ \\
\hline 2 & Cleaning the perineal area for hygiene & $1 / 0$ \\
\hline 3 & Holding plates and cups & $1 / 0$ \\
\hline 4 & Acepting coins and small objects in an open palm & $1 / 0$ \\
\hline 5 & Dressing & $1 / 0$ \\
\hline 6 & Writing & $1 / 0$ \\
\hline 7 & Taaking the palm to the occiput & $1 / 0$ \\
\hline 8 & Combing hair & $1 / 0$ \\
\hline 9 & Caatch a ball & $1 / 0$ \\
\hline 10 & Grasping & $1 / 0$ \\
\hline 11 & Holding & $1 / 0$ \\
\hline \multirow[t]{2}{*}{12} & Playing with toys & $1 / 0$ \\
\hline & Range of possible scores & 0 to 12 \\
\hline
\end{tabular}

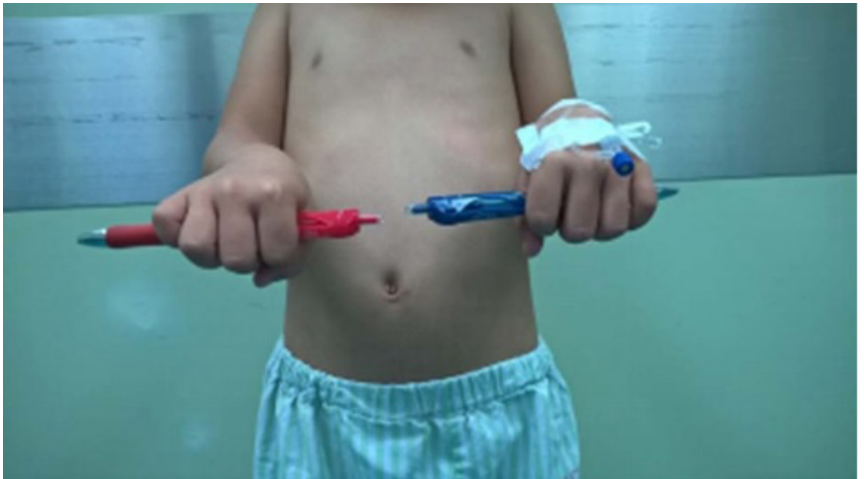

Figure 1. The right side showed the affected side before the operation, and that the red pen was consistent with the radius and ulna processus styloideus connecting line, showing that this patient's forearm on the right side was fixed in $90^{\circ}$ of pronation.

\subsection{Operation method}

Osteotomy plane was determined through positioning with $\mathrm{C}$-arm fluoroscopy in the operation (Figure 3 ). $1.0 \mathrm{~cm}$ distal to the inferior margin of proximal radioulnar joint (Figure 4) and metaphysis distal to radius (Figure 5) were selected respectively. The skin was cut by $2.0 \sim 3.0 \mathrm{~cm}$ longitudinally in the position of bone cutting layer by layer with periosteum exposed, and then the periosteum was open longitudinally, and the periosteum on two sides was protected with crow plate retractor carefully after the bone cutting part was exposed (Figure 6 and 7). Bone cutting was conducted after the bone cutting part was drilled with 2.0 kirschner wire. The periosteum was closed with 4-0 absorbable suture to guarantee the periosteum integrity and continuity. The wound was closed layer by layer. Minimally invasive minimum incision was adopted to reduce the postoperative soft tissue swelling, and also the bone cutting part was easy to expose. No tourniquet was used in the operation. No internal fixation was adopted (Figure 8 ) after bone cutting.


Figure 2. After compensation of shoulder joint and wrist joint on the right side, the angle of forearm pronation significantly increased to $135^{\circ}$ (about $45^{\circ}$ compensated).

Peripheral circulation conditions were observed After the closing of wound, forearm was rotated by $20 \sim 45^{\circ}$. The wound could be bounded up and fixed with cast (Figure 9) if there were no special circumstances. Cast change was conducted in ambulatory surgery room five days after the operation, during which, a small dose of intravenous anesthesia was carried out, and the cast change could be completed in 15 minutes generally. 


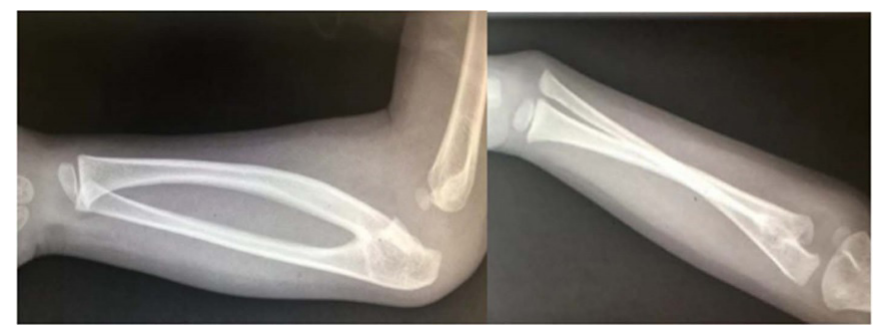

Figure 3. Anterioposterior and lateral films of right forearm before the operation.



Figure 4. Ulna osteotomy positioning.



Figure 5. Radius osteotomy positioning.

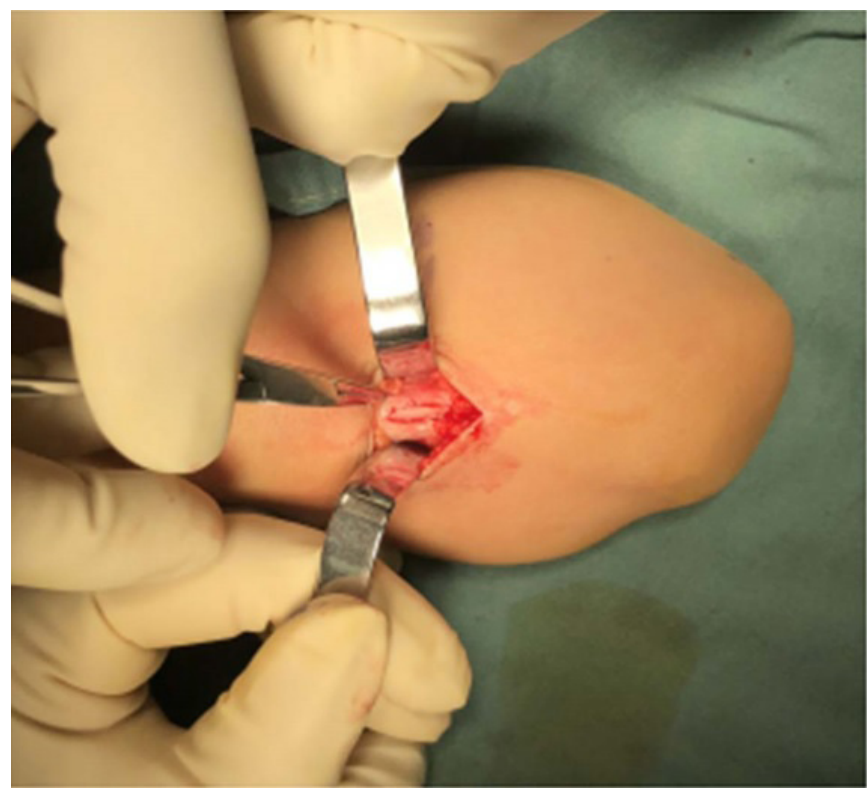

Figure 6. Ulna osteotomy incision, with periosteum opened longitudinally.

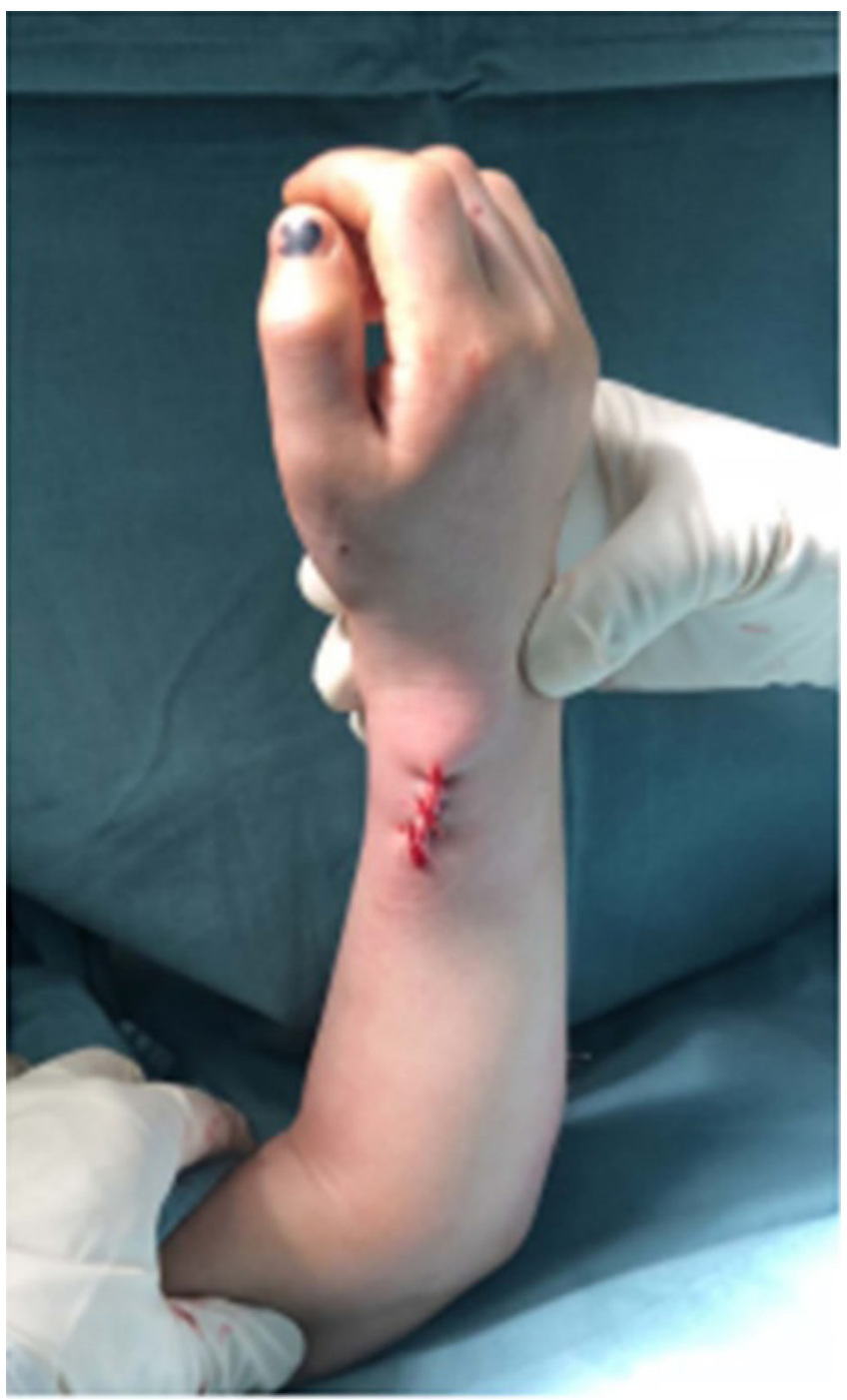

Figure 7. Radius osteotomy incision, about $3.0 \mathrm{~cm}$. 

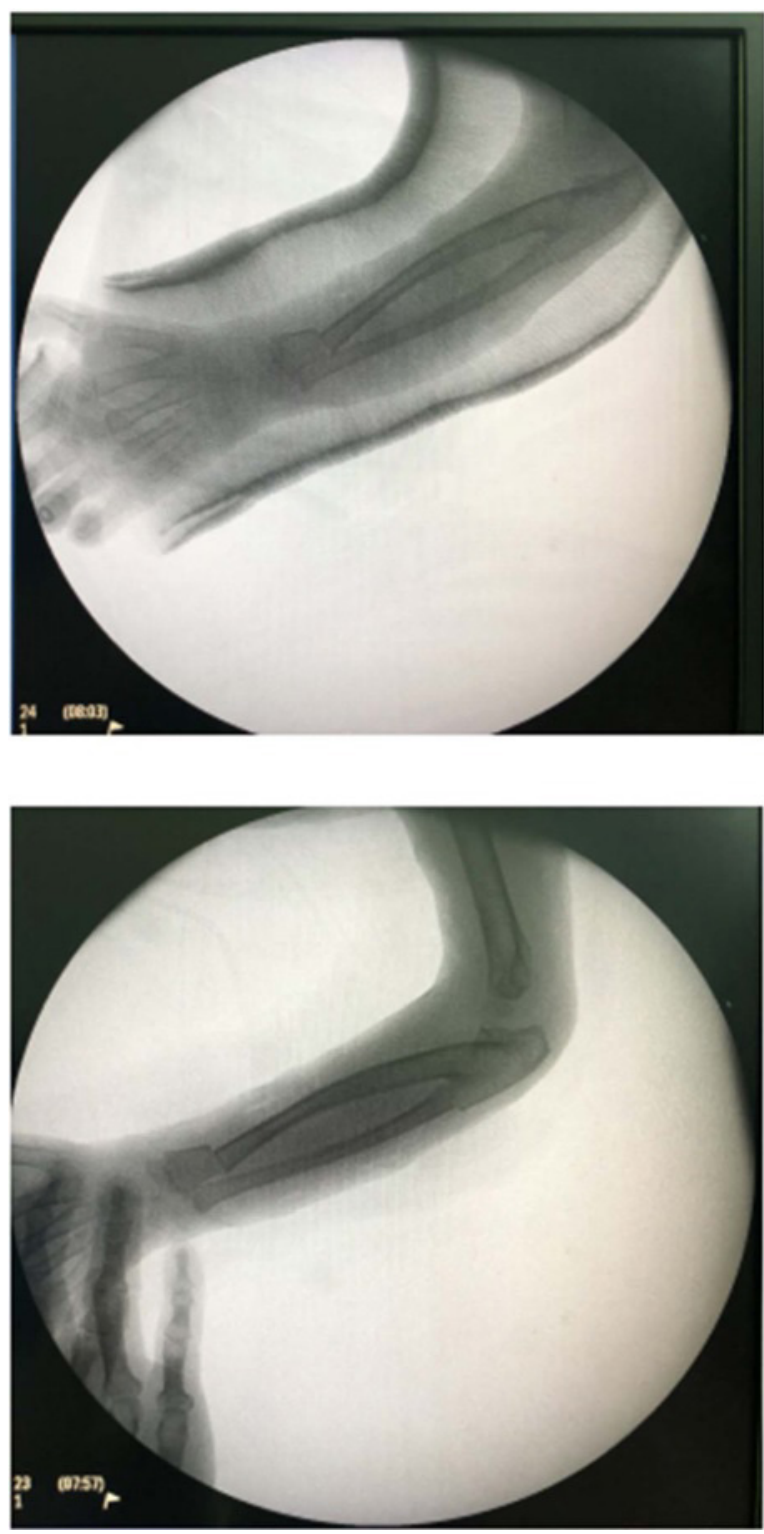

Figure 8. After completion of osteotomy, cast fixation was adopted rather than internal fixation.
The required position (Figure 10) was rotated to in stage II. The de-rotation angle would be reduced if any significant neurovascular symptom appeared, and the final position would be rotated to in stage III 5 days later. The cast fixation of elbow flexion would last for $4 \sim 6$ weeks. Plaster was removed and active exercise of elbow function was started $4 \sim 6$ weeks later. A film was taken in the follow-up visit two years later, and it's discovered that the fracture site completely realized bony union, and angulation deformity was also reshaped (Figure 11).

\subsection{Statistical method}

Statistical treatment was conducted with SPSS22.0 statistical software. Descriptive statistical analysis was developed to the patient's basic data before and after operation.

\section{Results}

General results: 12 child patients (16 limbs), average age: 6.25 (4 9) years old and the average follow-up visit time: 27.38 months. 12 of 16 limbs were corrected in position after one-time cast change, and the remaining 4 limbs of two patients needed to receive cast change for two times before correction. Neither one suffered related nervous and vascular complications, nor one suffered ischemic contracture after all the cases received cast fixation, and it took 8 weeks for their osteotomy parts to reach bony union averagely after operation. The average pronated deformity was $75.31^{\circ}$ (45 90) before operation, and the forearm was corrected to $45^{\circ}$ of pronation averagely after operation. The average $15^{\circ}$ of pronation upon bony union was reached finally after immobilization through cast change. The affected limb's functional evaluation before operation was averagely 5.75 scores (4 8); 12 movements could be completed fully after operation, i.e., functional evaluation reached 12 scores.

Please refer to Table 2 for details.

\section{Discussion}

\subsection{Indications of operation}

Cleary and Omer put forward the new type of proximal radioulnar joint fusion (Cleary \& Omer, 1985), however, such



Figure 9. Forearm of cast fixation in $50^{\circ}$ of pronation after operation. 


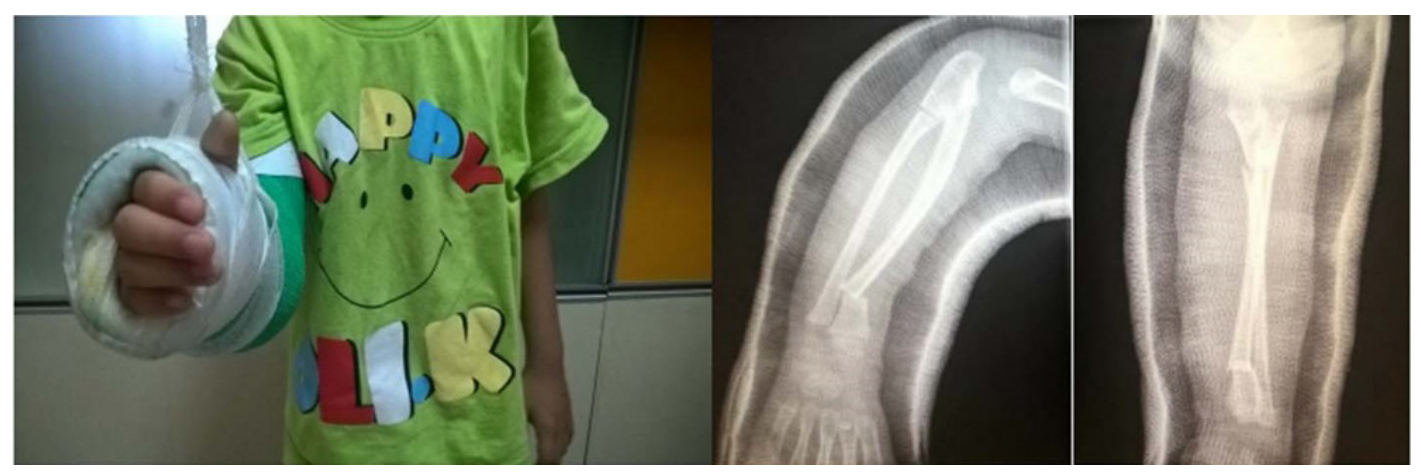

Figure 10. Cast change was conducted 5 days later after operation, and the forearm was fixed in $20^{\circ}$ of pronation.

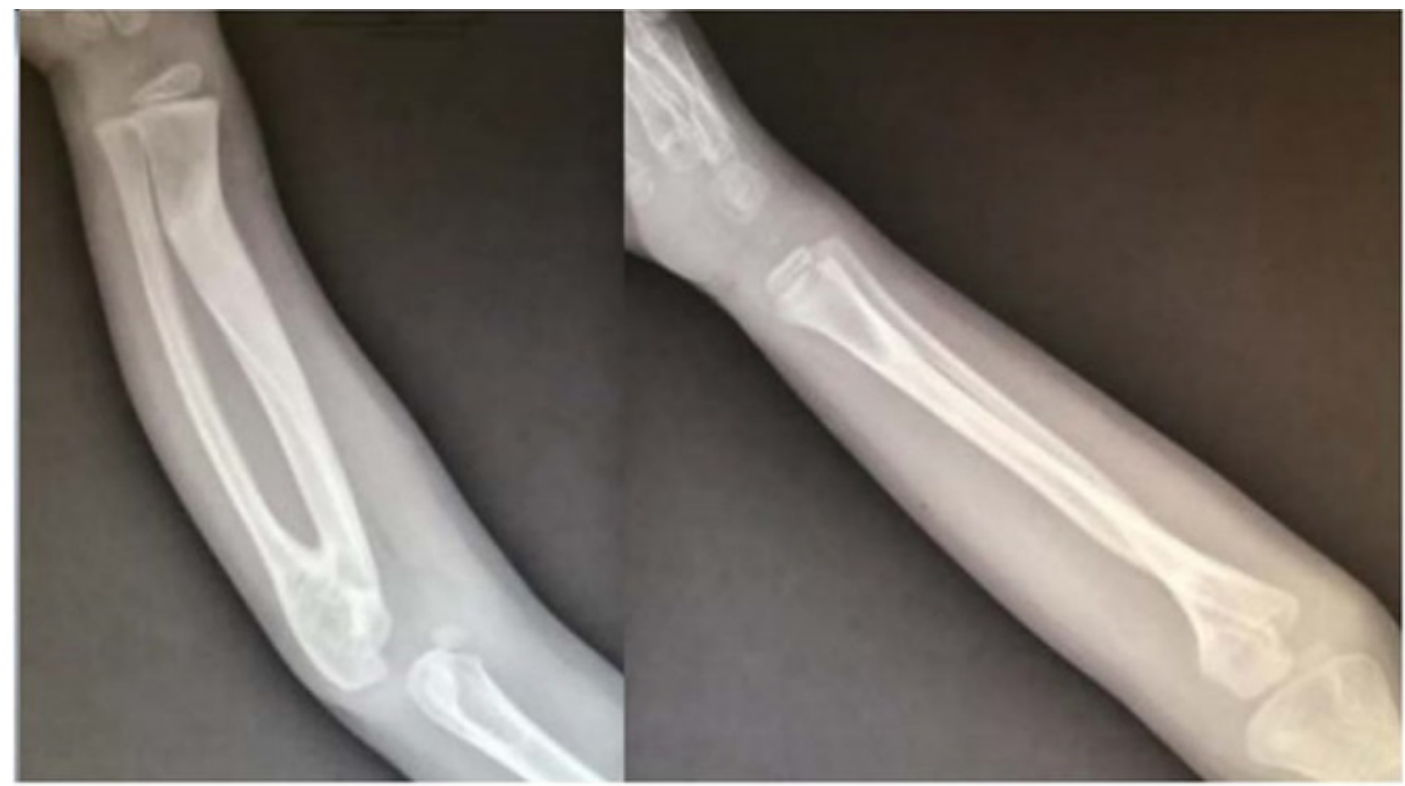

Figure 11. A film was taken in the follow-up visit two years later, and it's discovered that the fracture site completely realized bony union, and angulation deformity was also reshaped.

Table 2. Treatment results of 12 child patients.

\begin{tabular}{|c|c|c|c|c|c|c|c|c|c|c|c|}
\hline $\begin{array}{l}\text { Patient } \\
\text { No. }\end{array}$ & $\begin{array}{l}\text { Arm } \\
\text { No. }\end{array}$ & $\begin{array}{l}\text { OR } \\
\text { Age } \\
\text { Year }\end{array}$ & Gender & Side & $\begin{array}{l}\text { Preoperative } \\
\text { Activity score }\end{array}$ & $\begin{array}{c}\text { Preoperative } \\
\text { Fixed } \\
\text { pronation } \\
\text { Deformity } \\
\text { (Pronation) }^{\circ}\end{array}$ & $\begin{array}{c}\text { Postoperative } \\
\text { Fixed } \\
\text { pronation } \\
\text { Deformity } \\
\text { (Pronation) }^{\circ} \\
\end{array}$ & $\begin{array}{c}\text { After } 1^{\text {st }} \\
\text { Cast change } \\
\text { POSITION } \\
\text { (Pronation) }^{\circ}\end{array}$ & $\begin{array}{c}\text { After } 2^{\text {nd }} \\
\text { Cast change } \\
\text { POSITION } \\
\text { (Pronation) }^{\circ}\end{array}$ & $\begin{array}{l}\text { Follow- } \\
\text { up Time } \\
\text { Month }\end{array}$ & $\begin{array}{l}\text { Postoperative } \\
\text { Activity score }\end{array}$ \\
\hline 1 & 1 & 6 & $\mathrm{M}$ & $\mathrm{R}$ & 6 & 70 & 40 & 20 & 1 & 24 & 12 \\
\hline 2 & 2 & 4 & $\mathrm{~F}$ & $\mathrm{R}$ & 5 & 90 & 50 & 20 & I & 36 & 12 \\
\hline 3 & 3 & 6 & $\mathrm{M}$ & $\mathrm{R}$ & 6 & 80 & 50 & 20 & I & 24 & 12 \\
\hline 4 & 4 & 5 & $\mathrm{M}$ & $\mathrm{R}$ & 6 & 80 & 50 & 20 & I & 24 & 12 \\
\hline 4 & 5 & 5 & $\mathrm{M}$ & $\mathrm{L}$ & 6 & 70 & 30 & 0 & I & 24 & 12 \\
\hline 5 & 6 & 4 & $\mathrm{~F}$ & $\mathrm{R}$ & 5 & 90 & 50 & 20 & I & 24 & 12 \\
\hline 6 & 7 & 5 & $\mathrm{~F}$ & $\mathrm{R}$ & 7 & 70 & 40 & 20 & I & 36 & 12 \\
\hline 7 & 8 & 9 & $\mathrm{M}$ & $\mathrm{R}$ & 4 & 90 & 60 & 40 & 20 & 36 & 12 \\
\hline 7 & 9 & 9 & $\mathrm{M}$ & $\mathrm{L}$ & 4 & 90 & 60 & 30 & 0 & 36 & 12 \\
\hline 8 & 10 & 5 & $\mathrm{M}$ & $\mathrm{R}$ & 5 & 80 & 50 & 20 & 1 & 24 & 12 \\
\hline 9 & 11 & 5 & $\mathrm{~F}$ & $\mathrm{R}$ & 8 & 50 & 30 & 20 & 1 & 24 & 12 \\
\hline 9 & 12 & 5 & $\mathrm{~F}$ & $\mathrm{~L}$ & 8 & 45 & 20 & 0 & I & 24 & 12 \\
\hline 10 & 13 & 7 & $\mathrm{M}$ & $\mathrm{R}$ & 6 & 70 & 40 & 20 & I & 30 & 12 \\
\hline 11 & 14 & 7 & $\mathrm{M}$ & $\mathrm{R}$ & 6 & 60 & 40 & 20 & 1 & 24 & 12 \\
\hline 12 & 15 & 9 & $\mathrm{M}$ & $\mathrm{R}$ & 5 & 90 & 60 & 40 & 20 & 24 & 12 \\
\hline 12 & 16 & 9 & $\mathrm{M}$ & $\mathrm{L}$ & 5 & 80 & 50 & 20 & 0 & 24 & 12 \\
\hline
\end{tabular}


type was the same as the past ones, and it was not of great clinical significance. The better operation method relative to such type could not be selected according to the type. Also, there were no significant differences after the same operation between the two types (Miura et al., 1984). Therefore, we hold that the type above couldn't be taken as the reference basis of indications of operation.

Therefore, the indications of operation should be determined by the degree of deformity severity as well as the degree of daily functional loss according to Farzan et al. (2002). Ogino \& Hikino (1987) reported that the patients suffering serious functional loss had the average pronation of $60^{\circ}$, while those not suffering serious functional loss had the average pronation of $20^{\circ}$. Simmons put forward as early as in 1983 that, the cases without serious deformities and functional limitations could seek for conservative treatment rather than surgery, and pronation of $60^{\circ}$ was one of absolute indication of operation of de-rotation osteotomy; however, pronation of $15^{\circ} \sim 60^{\circ}$ was a relative indication, and that whether de-rotation operation was needed depended on the individual's daily living needs.

Therefore, the forearm pronation deformity angle and function scoring should be considered among our patients. The deformity will still be taken as surgical indication if the forearm pronation deformity angle is smaller than $60^{\circ}$, but the function scoring is smaller than 8 .

\subsection{Operative age}

Griffet et al. (1986) held that the optimal age of surgical intervention was $4 \sim 10$ years old. Farzan et al. (2002) suggested that the surgery should be arranged to the patients when they were $5 \sim 7$ years old. It's reported by literatures that, the smaller the surgical intervention was, the fewer neurovascular complications were.

The latter is considered as it's discovered in our this group of cases that, the older the children were, the slower their fracture healing was, the poorer their tolerance of forearm rotation was; and those needing three times of cast reshaping were all older in this group. This was consistent with the findings of Dalton et al. (2006), Hung (2008) and Shingade et al. (2014).

\subsection{Fusion joint dissociation}

There are many therapeutic methods for congenital proximal radioulnar joint fusion, including observation, rotation osteotomy, Ilizarov outrigger, and etc.

There are many operation methods attempting to make the forearm recover the rotation function. Many scholars like Miura et al.respectively reported the method to dissociate the joint fusion place and fill it with muscle or artificial synthetic materials, and other soft tissues; Hansen \& Andersen (1970) reported the excision of partial radius. However, the high incidence of joint re-fusion hindered the popularization and application of these methods. Therefore, they could become the reliable surgical methods to treat the congenital proximal radioulnar joint fusion.
The fused joints were tried to be dissociated in the past, but no good clinical result was obtained, and in the long-dated follow-up visit, it's discovered that the joint re-fusion appeared inevitably. Therefore, no such operation had been performed since 2010.

\subsection{Rotation osteotomy}

More and more scholars have selected to fix the forearm in a more functional position through rotation osteotomy to serve as a substituting surgical method of joint fusion separation. The operation methods were also different, mainly reflected in osteotomy in one stage or different stages, plane of osteotomy, internal fixation, cast fixation, and etc.

The reason of two-stage operation was that vascular nerve injury could be reduced. However, vascular nerve injury could be minimized through minimally invasive single dual-plane osteotomy combined with multi-sequence cast; therefore, there was no need to perform two times of osteotomy.

There were roughly about three positions of de-rotation osteotomy, respectively in the joint fusion position, on different planes of radius and ulna metaphysis, or in the metaphysis of distal radius.

There was a very high possibility of complications when level of osteotomy was at the level of radioulnar joint according to Simmons et al. (1983), Hankin et al. (1987), and Cleary \& Omer (1985). Osteotomy in the joint fusion part was likely to cause serious vasoneurotic complications, osteofascial compartment syndromes, forearm shrinkage or angulation, and even nerve injuries.

However, its vasoneurotic complications reduced significantly when the level of osteotomy was far away from the joint fusion. This point was consistent with the literature reports El-Adl (2007) and Shingade et al., (2014). Therefore, more and more scholars have selected to realize de-rotation through osteotomy at different levels of radius and ulna metaphysis, and it's reported that this operation method is simple and effective, with few complications.

One-stage osteotomy was adopted by us. The level of osteotomy was respectively $1.0 \mathrm{~cm}$ to metaphysis of distal radius and joint fusion of proximal ulna. Minimally invasive small incision was adopted to guarantee the forearm appearance and also protect the periosteum and vascular nerve tissues to the largest degree.

\subsection{Internal fixation}

It is still controversial on whether internal fixation is needed. El-Ad (2007) reported two-stage dual-plane rotational osteotomy, and the end of osteotomy was not fixed with kirschner wire during operation, but only fixation of POP cast was depended on. However, de-rotation loss could be caused due to cast loosening after operation. Murase et al.and other authors also reported and discovered that the angle of correction would be lost through single cast fixation, and it's therefore recommended to fix the end of osteotomy with kirschner wire.

Subsequent sequence cast orthotics rather than internal fixation was adopted after operation. This was the biggest 
difference from other operation methods. This method was safe, effect, and could avoid the loss of reshaping due to cast loosening. This was sourced from our one case of failure.

\subsection{Sequence cast fixation}

The method was adopted to fix the fracture end with elastic intramedullary nail in the early cases as elastic intramedullary nail was more flexible than kirschner wire, and the angle of forearm rotation could be adjusted as required after operation. However, one case suffered serious neurovascular symptom after operation, and he/she could be recovered even after the removal of cast, and it was possibly because that this patient had suffered a serious deformity, and his/her forearm pronation before operation was $80^{\circ}$, and during operation, it was corrected to pronation of $20^{\circ}$, and then elastic intramedullary nail was used for fixation. After removal of cast, due to the existence of elastic intramedullary nail, the angle of pronation couldn't be reduced, so the symptoms couldn't be improved. The operation had to be performed in the operation room again to take out the intramedullary nail, reduce the de-rotation angle, and fix the forearm in the $50^{\circ}$ of pronation. The neurovascular symptom was significantly improved immediately. Cast change was conducted 5 days later after operation as this patient under intravenous anesthesia and fixed his/her forearm in the $20^{\circ}$ of pronation, and also no fixation was adopted. After operation, this patient didn't have the neurovascular symptom.

Afterwards, this method was used for treating the patients. The reason that we didn't adopt internal fixation is as follows:

1. Due to no internal fixation, cast could be dismantled timely to realize restoration and improve the vascular and nervous tension when related vascular and nervous complications appeared in case of excessive correction and rotation.

2. Three two or three sequence cast fixation, the angle needing de-rotation could be realized in different times, so as to reduce the traction to vascular and nervous tissues. The blood supply situation of soft tissues was improved five days later after osteotomy, only soft callus was formed, and it was a better chance of cast reshaping. The patient with serious deformity possibly needed the readjustment of cast to an ideal position of fixation. The maximum effect of reshaping could be achieved while nervus vascularis was protected in this way.

3. It's also discovered among our cases that, with the soft tissue swelling fading away, partial angle of correction was lost due to cast loosening, however, the angle of correction could be obtained again through the subsequent cast fixation again. As soft tissue swelling already faded away, the cast would be more clinging to the tissues, and no cast loosening would appear in the subsequent cast fixation.

4. The patients could avoid from receiving the further surgery of internal fixator removal. Although once more cast fixation could need anesthesia again, yet this could be completed in onetime period of hospitalization, and also only few intravenous anesthetic was needed.
5. The periosteum was cut open longitudinally during process of osteotomy, and the continuity of periosteum should be protected with care. The periosteum was sutured with 4-0 absorbable suture after completion of periosteum. This could guarantee the stability of osteotomy end. Therefore, the bony union of osteotomy end could be guaranteed only by depending on the cast.

\subsection{Position of fixation}

According to Green \& Mital (1979), as for a patient with bilateral involvement, the forearm of dominant side should be fixed in the $30 \sim 45^{\circ}$ of pronation, while the non-dominant side should be fixed in the $20 \sim 35^{\circ}$ of supination; as for a patient with unilateral involvement, the ideal position of fixation was $20 \sim 35^{\circ}$ of supination. the non-dominant side should be fixed in $0 \sim 20^{\circ}$ of supination, and the dominant side should be fixed in $0 \sim 20^{\circ}$ of pronation according to Ogino \& Hikino (1987), fixation in $10^{\circ}$ of supination was recommended according to Ramachandran et al. (2005)., for shoulder joint and wrist joint could compensate the movement of pronation in part.

As for the ultimate position of correction, it was determined in $20^{\circ}$ of forearm pronation when elbow was bent by $90^{\circ}$ at the dominant side, and in the neutral position of forearm when elbow was bent by $90^{\circ}$ at the non-dominant side. The movement of forearm pronation mostly could be obtained through compensation of shoulder joint and elbow joint according to literature report (Figure 1 and 2); however, the forearm supination movement couldn't be obtained through the compensation of two joints above. Therefore, the forearm fixed in $20^{\circ}$ of forearm pronation could satisfy the most movement of daily living.

\section{Conclusion}

This surgical operation is easy to operate, with good operation result and big range of correction. It can also effectively avoid the occurrence of angioneurotic complications after operation with a high safety. Therefore, it is an ideal alternative method to treat the congenital proximal radioulnar joint fusion in the present stage when joint fusion dissociation operation is not matured.

\section{Ethical approval}

All procedures performed in studies involving human participants were in accordance with the ethical standards of the institutional and/or national research committee and with the 1964 Helsinki declaration and its later amendments or comparable ethical standards. This research has been approved by the IRB of the authors' affiliated institutions.

\section{Conflict of Interests}

The authors declare that they have no conflict of interest.

\section{References}

Cleary, J. E., \& Omer, G. E. Jr (1985). Congenital proximal radioulnar synostosis. Natural history and functional assessment. The Journal of Bone and Joint Surgery, 67(4), 539-545. http://dx.doi. org/10.2106/00004623-198567040-00006. PMid:3980498. 
Dalton, J. F., Manske, P. R., Walker, J. C., \& Goldfarb, C. A. (2006). Ulnar non-union after osteoclasis for rotational deformities of the forearm. The Journal of Hand Surgery, 31(6), 973-978. http://dx.doi. org/10.1016/j.jhsa.2006.03.006. PMid:16843158.

El-Adl, W. (2007). Two-stage double-level rotational osteotomy in the treatment of congenital radioulnar synostosis. Acta Orthopaedica Belgica, 73(6), 704-709. PMid:18260481.

Farzan, M., Daneshjou, S. M., \& Espandar, R. (2002). Congenital radioulnar synostosis, a report of 11 cases and review of literature. Acta Medica Iranica, 40(2), 126-131.

Green, W. T., \& Mital, M. A. (1979). Congenital radio-ulnar synostosis: surgical treatment. The Journal of Bone \& Joint Surgery, 61(5), 738-743. http://dx.doi.org/10.2106/00004623-197961050-00015. PMid:457717.

Griffet, J., Berard, J., Michel, C. R., \& Caton, J. (1986). Congenital superior radioulnar synostosis. A study of 43 cases. International Orthopaedics, 10(4), 265-269. PMid:3804528.

Hankin, F. M., Smith, P. A., Kling, T. F. Jr, \& Louis, D. S. (1987). Ulnar nerve palsy following rotational osteotomy of congenital radioulnar synostosis. Journal of Pediatric Orthopedics, 7(1), 103-106. http:// dx.doi.org/10.1097/01241398-198701000-00022. PMid:3793902.

Hansen, O. H., \& Andersen, N. O. (1970). Congenital radio-ulnar synostosis. Report of 37 cases. Acta Orthopaedica Scandinavica,
41(3), 225-230. http://dx.doi.org/10.3109/17453677008991509. PMid:5486179.

Hung, N. N. (2008). Derotational osteotomy of the proximal radius and the distal ulna for congenital radioulnar synostosis. Journal of Children's Orthopaedics, 2(6), 481-489. http://dx.doi.org/10.1007/ s11832-008-0146-5. PMid:19308546.

Miura T., Nakamura R., Suzuki M., \& Kanie J. (1984). Congenital radioulnar synostosis. Journal of Hand Surgery, 9(2),153-155.

Ogino, T., \& Hikino, K. (1987). Congenital radio-ulnar synostosis: compensatory rotation around the wrist and rotation osteotomy. The Journal of Hand Surgery, 12(2), 173-178. http://dx.doi. org/10.1016/0266-7681(87)90006-4. PMid:3624970.

Ramachandran, M., Lau, K., \& Jones, D. H. (2005). Rotational osteotomies for congenital radioulnar synostosis. The Journal of Bone and Joint Surgery, 87(10), 1406-1410. http://dx.doi.org/10.1302/0301620X.87B10.16445. PMid:16189317.

Shingade, V. U., Shingade, R. V., \& Ughade, S. N. (2014). Results of single-staged rotational osteotomy in a child with congenital proximal radioulnar synostosis. Journal of Pediatric Orthopedics, 34(1), 63-69. http://dx.doi.org/10.1097/BPO.0b013e3182a00890. PMid:23863412.

Simmons, B. P., Southmayd, W. W., \& Riseborough, E. J. (1983). Congenital radioulnar synostosis. The Journal of Hand Surgery, 8(6), 829-838. http://dx.doi.org/10.1016/S0363-5023(83)80078-1. PMid:6643957. 